\title{
PEMANFAATAN APLIKASI E-COMMERCE BERBASIS WEB MENGGUNAKAN FRAMEWORK CODEIGNITER (STUDI KASUS : DISTRO PAK EKO)
}

\author{
Yustina Meisella Kristania \\ Sistem Informasi, STMIK Nusa Mandiri Jakarta \\ yustina.yms@nusamandiri.ac.id
}

\begin{abstract}
The progress of internet technology for now is very helpful in almost all fields of life, including in the business sector of commerce. E-commerce is one of the technologies that support the development of today's trading world. Online sales can make it easier for small to medium-sized businesses because of the lack of capital for financing rental premises, determining strategic marketing points, to the amount of electricity financing. This website application is an online sales system using internet technology, to facilitate prospective buyers in conducting transactions through this media. The web-based e-commerce application on Eko Distro is made using the PHP programming language with the Codelgniter framework and MySQL database. Analysis of problems in the development of e-commerce applications uses analysis and PIECES requirements. It is expected that with the existence of an additional service door at Distro, Pak Eko will be able to facilitate the long-distance transaction process besides having to visit the distro for a long time.
\end{abstract}

\section{Keywords: internet, e-commerce, website, framework codeigniter}

\begin{abstract}
Abstrak - Kemajuan teknologi internet untuk saat ini sangat membantu hampir diseluruh bidang kehidupan, termasuk pada bidang usaha perdagangan. E-commerce merupakan salah satu teknologi yang mendukung perkembangan dunia perdagangan saat ini. Penjualan online dapat mempermudah badan usaha kecil hingga menengah karena sedikitnya modal pembiayaan sewa tempat, penentuan titik strategis pemasaran, sampai dengan besarnya pembiayaan listrik. Aplikasi website ini adalah sebuah sistem penjualan online menggunakan teknologi internet, untuk mempermudah calon pembeli dalam melakukan transaksi melalui media ini. Aplikasi e-commerce berbasis web pada Distro Pak Eko ini dibuat menggunakan bahasa pemrograman PHP dengan framework Codelgniter dan basis data MySQL. Analisis masalah dalam pengembangan aplikasi e-commerce ini menggunakan analisis dan kebutuhan PIECES. Diharapkan dengan adanya satu pintu layanan tambahan pada Distro Pak Eko ini akan mampu memudahkan dalam proses transaksi jarak jauh selain harus mengunjungi distro dengan waktu yang lama.
\end{abstract}

\section{Kata kunci : internet, e-commerce, website, framework codeigniter}

\section{A. PENDAHULUAN}

Internet tidak hanya untuk sarana informasi maupun entertainment namun saat ini banyak digunakan untuk transaksi secara online. Hal ini sangat menguntungkan karena dengan menggunakan internet, maka bisnis akan memiliki jangkauan yang lebih luas. Bisnis internet merupakan suatu bisnis yang dalam prosesnya baik dalam pemasaran, pemesanan maupun transaksinya menggunakan media internet. Bisnis ini juga disebut e-commerce. E-commerce memberikan kemudahan kepada konsumen dalam memilih produk tanpa harus datang langsung ke distro.

Distro Pak Eko merupakan sebuah distro yang menjual fashion secara lengkap dengan gaya yang up to date. Distro Pak Eko masih menggunakan sistem pelayanan transkasi yang sederhana. Dengan hanya dicatat pada sebuah buku, pelayanan kepada pelanggan menjadi kurang maksimal. Meski telah menggunakan kalkulator, penghitungan transaksi masih memiliki kelemahan yaitu sering terjadi kesalahan penghitungan karena faktor salah pembacaan kode barang. Dalam pendataan stok barang juga hanya mengandalkan pencatatan pada sebuah buku tanpa dukungan sebuah komputer. Maka dibutuhkan solusi untuk meningkatkan pelayanan konsumen di Distro Pak Eko yaitu dengan membuat website e-commerce Distro Pak Eko. Dengan adanya sistem ini diharapkan dapat memudahkan proses pemasaran produk dan juga memudahkan dalam menghitung jumlah transaksi di Distro Pak Eko, serta semakin memudahkan 
konsumen untuk memilih dan memesan produk yang diinginkan sehingga dapat meningkatkan omset penjualan Distro Pak Eko.

\section{B. TUJUAN DAN MANFAAT}

Tujuan Penelitian

Menghasilkan rancangan sistem informasi berupa website e-commerce yang membantu penjualan, jumlah ketersediaan barang, dan laporan penjualannya.

\section{Manfaat Penelitian}

1. Memudahkan pihak Distro Pak Eko untuk mengelola data barang.

2. Membantu pihak Distro Pak Eko untuk mempromosikan barang-barang yang dijual.

3. Memudahkan pelanggan untuk memesan barang karena website beroperasi 24 jam.

4.Membantu pelanggan untuk mendapatkan informasi biaya pengiriman

\section{PENELITIAN TERDAHULU}

Penelitian sebelumnya yang dilakukan oleh Yohana Arum Widati dan Rahajeng Ratnaningsih dengan judul Sistem informasi penjualan dan penilaian batu mulia Berbasis web sentra industri ud. Sony permata pacitan. Metode yang digunakan dalam pembuatan perangkat lunak ini adalah metode waterfall, bahasa pemrograman yang digunakan adalah PHP dan dengan database MySQL. Pembuatan website dapat membantu UD. Sony Permata dalam menyampaikan informasi tentang batu mulia dan memberikan layanan pemesanan secara online, serta mempermudah konsumen dalam membandingkan produk berdasarkan penilaian kriteria batu mulia.

Penelitian sebelumnya yang dilakukan oleh Sandy Kosasi dengan judul perancangan sistem e-commerce untuk Produk pembuatan kue. Metode yang digunakan dalam pembuatan perangkat lunak ini adalah metode agile dengan pendekatan Feature Driven Development (FDD), bahasa pemrograman yang digunakan adalah pemrograman PHP dengan framework Codelgniter. Melalui sistem E-Commerce, ING's Kitchen dapat memperluas jangkauan pemasaran dengan memperkenalkan dan menjual produk-produk peralatan untuk membuat kue.

\section{METODE ANALISIS PIECES}

Menurut Wukil Ragil (2010:17), metode PIECES adalah metode analisis sebagai dasar untuk memperoleh pokok-pokok permasalahan yang lebih spesifik. Dalam menganalisis sebuah sistem, biasanya akan dilakukan terhadap beberapa aspek antara lain adalah kinerja, informasi, ekonomi, keamanan aplikasi, efisiensi dan pelayanan pelanggan. Analisis ini disebut dengan PIECES Analysis (Performance, Information, Economy, Control, Eficiency and Service).

\section{E. LANDASAN TEORI \\ 1. Web Server}

Menurut (Alexander, 2013) "Web Server adalah sebuah komputer terdiri dari perangkat keras dan perangkat lunak. Secara bentuk dan fisik dan cara kerjanya,perangkat keras web server tidak berbeda dengan komputer rumah atau PC, yang membedakan adalah kapasitas dan kapabilitasnya".

Web server merupakan perangkat lunak pada server yang memiliki fungsi sebagai penerima permintaan (request) yang berupa halaman web dari client mengirim kembali (respons) hasil yang diminta dalam bentuk halamanhalaman web. Jadi, dapat disimpulkan web server merupakan sebuah aplikasi yang digunakan untuk menampilkan halamanhalaman website yang disimpan pada localhost agar dapat dibaca oleh pengguna.

\section{Bahasa Pemrograman}

\section{a) Hypertext markup language (HTML)}

Menurut (Edy Winarno ST, 2013), "HTML merupakan singkatan dari Hypertext Markup Language, artinya bahasa ini adalah bahasa markup untuk memformat konten halaman web".

HTML adalah bahasa pemrograman yang bebas, dan tidak dimiliki oleh siapa pun, pengembangannya dilakukan oleh banyak orang, banyak pihak diseluruh dunia dan bisa dikatakan sebagai sebuah bahasa yang dikembangkan bersama-sama secara global

\section{b) Hypertext Prepocessor (PHP)}

Menurut (Anhar S. , 2010), "PHP singkatan dari Hypertext Prepocessor yaitu bahasa pemrograman web server-side yang bersifat open source. PHP merupakan script yang terintegrasi dengan HTML dan berada pada server (Server Side HTML Embeded Scripting)".

\section{My Structure Query Language (MySQL)}

Menurut (Anhar S. , 2010), "My Structure Query Language (MySQL) adalah sebuah perangkat lunak sistem manajemen basis data SQL Database Management System (DBMS) dari sekian banyak DBMS seperti oracle, MS SQL, Postagre SQL, dan lain-lain. MySql merupakan DBMS yang multithread, multi user 
yang bersifat gratis dibawah lisensi GNU General Publuc Lisenci (GPL)".

\section{CODEIGNITER}

Menurut (V.P, 2016), "CODEIGNITER adalah aplikasi opensource berupa framework dengan model Model, View, Controller (MVC) untuk membangun website dinamis dengan menggunakan PHP"

\section{Entity Relationship Diagram (ERD)}

Menurut (Andriansyah, 2016), "Entity Relationship Diagram merupakan diagram yang menggambarkan hubungan yang terjadi antara tabel. ERD tidak menggambarkan bagaimana jalannya sebuah program layaknya diagram alir (flowchart)".

Menurut Fathansyah dalam (Fatmawati, 2016), "Entity Relationship Diagram adalah diagram yang berisi komponen-komponen himpunan entitas dan himpunan relasi yang masingmasing dilengkapi dengan atribut- atribut yang mempresentasikan seluruh fakta dari dunia nyata yang kita tinjau".

\section{Logical Relational Struktur (LRS)}

Menurut (Andriansyah, 2016), "LRS merupakan transformasi dari penggambaran ERD dalam bentuk yang lebih jelas dan mudah untuk dipahami. Penggambaran LRS hampir mirip dengan penggambaran normalisasi file. Hanya saja tidak digambarkan simbol asterix ${ }^{*}$ ) sebagai simbol kunci utama (primary key) dan kunci tamu (foreign key)".

Logical Record Structure dibentuk dengan nomor dari tipe record. Beberapa tipe record digambarkan oleh kotak empat persegi panjang dan dengan nama yang unik. Beda LRS dengan diagram entity relationship diagram nama tipe record berada diluar kotak field tipe record ditempatkan. LRS terdiri dari link-link diantara tipe record. Link ini menunjukkan arah dari satu tipe record lainnya.

Banyak link dari LRS yang diberi tanda fieldfield yang kelihatan pada kedua link tipe record. Penggambaran LRS mulai dengan menggunakan model yang dimengerti. Dua metode yang dapat digunakan, dimulai dengan hubungan kedua model yang dapat dikonversikan ke LRS. Metode yang lain dimulai dengan Entity Relationship Diagram dan langsung dikonversikan ke LRS.

\section{F. METODE PENELITIAN}

Metode yang digunakan pada penelitian ini yaitu:

1. Observasi Pengamat (Observation)
Pada metode ini penulis melakukan pengamatan secara langsung terhadap obyek yang diteliti yaitu mengenai prosedur yang sedang berjalan pada Distro Pak Eko

2. Wawancara (Interview)

Dalam penulisan laporan akhir ini, untuk mendapatkan informasi secara lengkap maka penulis melakukan metode tanya jawab langsung dengan Pemilik Distro Pak Eko mengenai prosedur alur kegiatan transaksi pada Distro Pak Eko

3. Studi Pustaka

Untuk melengkapi data yang diperlukan oleh penulis, penulis melakukan studi pustaka yaitu suatu metode pengumpulan data yang dilakukan dengan klasifikasi bahan-bahan tertulis yang berhubungan dengan permasalahan, baik dari sumber dokumen maupun buku-buku.

\section{G. RANCANGAN BASIS DATA}

\section{Use Case Sistem}

Untuk memudahkan dalam perancangan aplikasi web ini, digunakan bahasa pemodelan Unified Modelling Language (UML). Perancangan sistem yang digunakan pada diagram use case Gambar 1 ini menggunakan aktor Pengunjung dan aktor Sistem atau Administrator

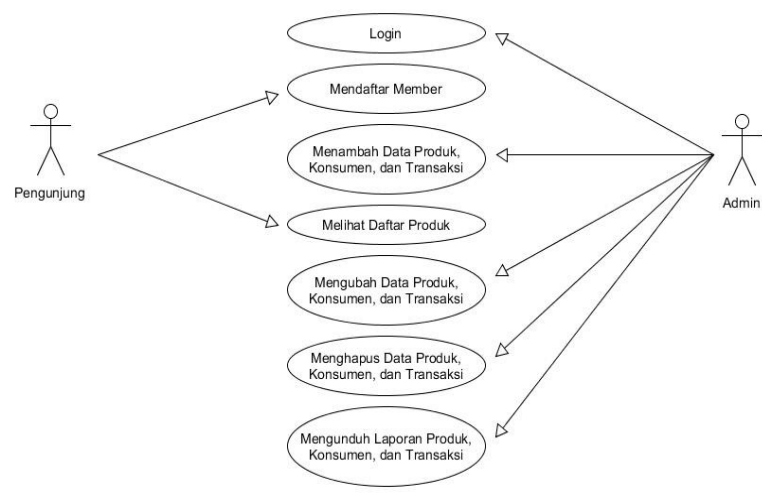

Gambar 1. Use Case Diagram

\section{Entity Relationship Diagram (ERD)}

Gambar 2 memperlihatkan Entity Relationship Diagram dari aplikasi web Distro Pak Eko 


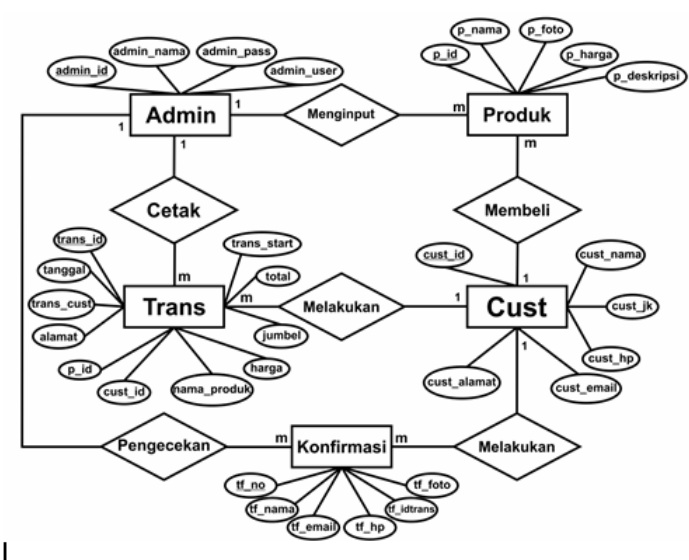

Gambar 2. Entity Relationship Diagram

3. Logical Record Structure (LRS)

Gambar 2 memperlihatkan Logical Record Structure dari aplikasi web Distro Pak Eko Logical

Record

Structure

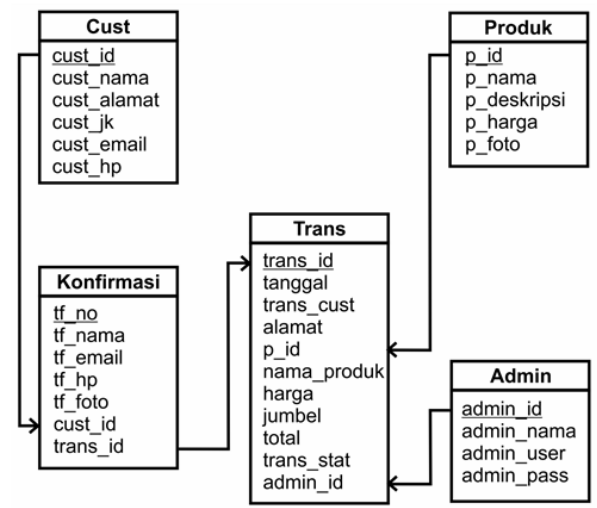

\section{Gambar 3. Logical Record Structure}

\section{H. HASIL DAN PEMBAHASAN}

1. Performance

Kinerja disini berperan penting sebagai penilai apakah proses yang ada masih dapat ditingkatkan kinerjanya dan melihat sejauh mana sistem informasi dapat menghasilkan tujuan yang diinginkan. Pada aplikasi e-commerce berbasis web ini, transaksi dilakukan di distro sehingga terbatas tempat dan waktu. Dengan menggunakan sistem berbasis web akan membuat proses transaksi tidak terbatas waktu serta dapat dilakukan dimana saja

\section{Information}

Penilaian yang dilakukan pada prosedur yang ada, untuk memperbaiki kualitas informasi yang dihasilkan menjadi semakin baik. Informasi yang disajikan harus mempunyai nilai guna. Informasi produk selama ini hanya dapat diperoleh dengan langsung mengunjungi distro . Dengan bantuan sistem informasi berbasis website ini, informasi dapat terakses dengan lebih mudah.

\section{Economics}

Penilaian terhadap prosedur yang ada saat ini apakah masih dapat ditingkatkan nilai guna dan dapat diturunkan biaya penyelenggaraannya. Pada Distro Eko media promosi produk yang ditawarkan masih memakan waktu dan biaya. Dengan menggunakan sistem informasi ini promosi produk yang ditawarkan cukup dengan mengupload informasi produk pada web.

\section{Control}

Menilai apakah prosedur saat ini dapat ditingkatkan sehingga kualitas kontrol dan kemampuan untuk mendeteksi kesalahan juga semakin baik. Saat ini semua aktifitas di distro pak eko penjualannya dilakukan secara offline di distro. Transaksi akan semakin mudah dengan dilakukan secara online.

\section{Efficiency}

Penilaian terhadap prosedur yang ada saat ini, apakah masih dapat diperbaiki sehingga mampu meningkatkan keefisiensian operasi dari sistem manual. Informasi dan promosi yang berjalan pada distro pak eko masih menggunakan hard copy sehingga masih memakan waktu yang cukup lama dalam menyampaikan pesan kepada calon konsumen. Dengan menggunakan sistem informasi berbasis web, informasi dan promosi menjadi lebih cepat dan dapat diakses setiap saat.

\section{Services}

Menilai apakah prosedur yang ada masih dapat diperbaiki kemampuannya untuk mencapai peningkatan kualitas layanan. Pelayanan pada transaksi konvensional Distro Pak Eko masih kurang maksimal, karena calon konsumen masih harus mendatangi distro untuk melakukan transaksi. Dengan pelayanan yang diberikan oleh sistem informasi berbasis web ini, transaksi dapat dilakukan oleh setiap konsumen diseluruh Indonesia tanpa harus datang langsung.

1. Halaman Utama

Halaman utama merupakan halaman yang pertama kali muncul saat mengunjungi website 
a. Home

Home merupakan halaman utama yang muncul saat pertama kali masuk ke website. Home menampilkan berbagai menu yang berhubungan dengan website tersebut.

\section{b. Produk}

Menu produk berisi produk-produk dari Distro Pak Eko. Melalui menu ini konsumen dapat menemukan berbagai macam produk dari Distro Pak Eko.

\section{c. Konfirmasi Pembayaran}

Pada menu ini, konsumen yang telah membayar produk yang dipilih kemudian melakukan konfirmasi pembayaran kepada admin.

\section{d. About Us}

Pada menu about us ini terdapat profil singkat tentang Distro Pak Eko.

\section{e. Kolom Pencarian}

Dengan adanya kolom pencarian ini maka konsumen akan lebih mudah dalam mencari produk yang diinginkan.

\section{f. Daftar}

Melalui menu daftar, konsumen dapat melakukan registrasi akun yang nantinya digunakan dalam pembelian produk di Distro Pak Eko.

\section{g. Login Admin}

Digunakan oleh admin untuk masuk ke halaman admin dengan menggunakan username dan password yang telah tersimpan di database.

h. Slide Show

Slide Show berisi gambar-gambar produk yang berganti secara kontinyu.

\section{i. Produk terbaru}

Melalui menu ini konsumen dapat melihat produk-produk terbaru dari Distro Pak Eko yang lengkap dengan nama produk dan juga harga dari produk tersebut.

\section{j. Produk Terlaris}

Menu Produk Terlaris ini berisikan gambar produk beserta nama dan harga yang paling laris atau paling diminati oleh para konsumen.

\section{k. Produk Diskon}

Menu ini digunakan untuk media promosi produk diskon dari Distro Pak Eko. Selain itu, konsumen juga menjadi lebih mudah mendapatkan produk diskon melalui menu ini.

I. Video

Menu Video digunakan sebagai media promosi Distro Pak Eko. Pada menu ini ada berbagai macam video antara lain Kenapa Harus Distro Pak Eko?, 2014 Distro Lookbook, Tips Tampil Casual, Pak Eko Daily Life dan lain sebagainya.

m. Informasi

Menu ini menginformasikan kepada konsumen tentang Distro Pak Eko, kemudian tentang cara custom pakaian, informasi tentang size cart, syarat dan ketentuan, dan ada juga $F A Q$ yang berisi pertanyaan dan jawaban yang sering ditanyakan kepada Distro Pak Eko.

\section{n. Layanan}

Distro Pak Eko memiliki beberapa layanan antara lain Home Service, Member, Partner/Reseller dan Store. Konsumen dapat mengakses layanan tersebut melalui menu Layanan yang tersedia di website Distro Pak Eko.

\section{o. Kontak}

Menu Kontak berisi tentang alamat Distro Pak Eko, nomor telepon (Call Center, SMS/WA) yang dapat dihubungi kemudian ada juga akun media sosial. Melalui menu ini konsumen menjadi lebih mudah menghubungi pihak Distro Pak Eko sehingga bisa mendapatkan informasi yang lebih banyak.

p. Footer

Pada bagian footer terdapat googlemaps yang akan memudahkan konsumen untuk datang ke Distro Pak Eko.

2. Halaman Admin

\section{a. Data Produk}

Admin dapat mengolah informasi produkproduk Distro Pak Eko melalui menu Data Produk. Dalam menu ini ada fitur tambah produk, kolom pencarian, tombol reset, tombol edit dan hapus produk, kemudian ada juga fitur export ke excel.

\section{b. Data Customer}

Admin mengolah data pelanggan melalui menu Data Customer. Data Customer memiliki fitur yang hampir sama dengan fitur di dalam Data Produk yaitu tambah customer, kolom pencarian, tombol reset, 
tombol edit dan hapus produk, kemudian ada juga fitur export ke excel.

c. Transaksi

Menu transaksi berisi tentang data transaksi yang telah dilakukan. Dalam menu ini terdapat fitur tambah transaksi, kolom pencarian, tombol reset dan fitur export ke excel.

\section{USER INTERFACE}

1. Tampilan Login Admin Admin dapat mengakses halaman dengan menggunakan username dan password yang telah tersimpan di database.

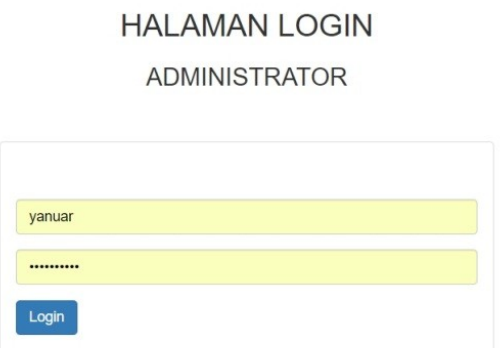

\section{Gambar 4. Login Admin}

2. Daftar Produk

Daftar produk berisi produk-produk dari Distro Pak Eko. Melalui menu ini konsumen dapat menemukan berbagai macam produk dari Distro Pak Eko.

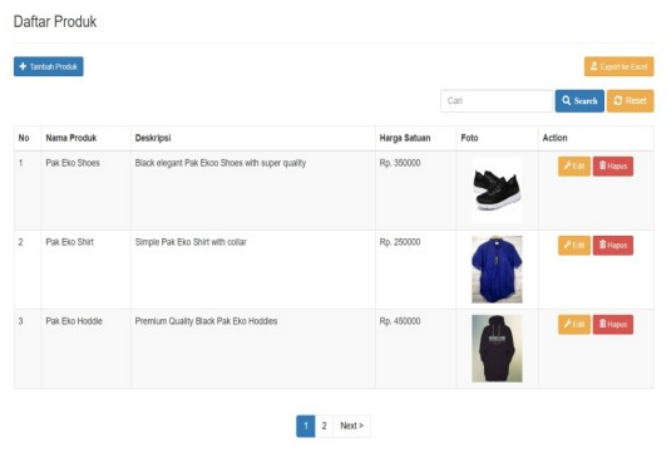

\section{Gambar 5. Daftar Produk}

3. Daftar Cutomer

Melalu layanan daftar customer, Admin dapat mengolah data pelanggan melalui menu Data Customer.

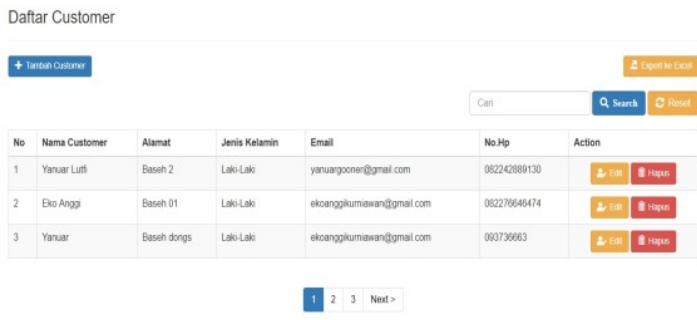

\section{Gambar 6. Daftar Customer}

4. Daftar Transaksi

Pada halaman daftar transaksi berisi fitur tambah transaksi, kolom pencarian, tombol reset dan fitur export ke excel.

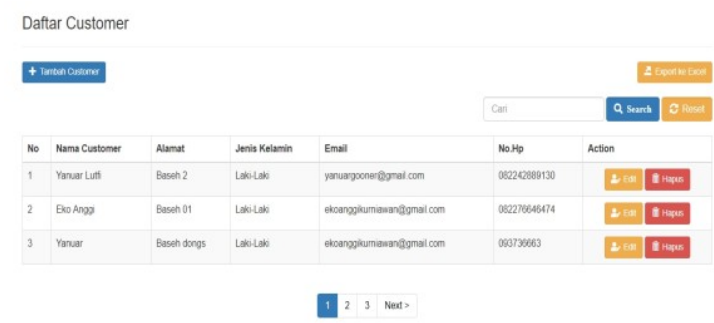

\section{Gambar 7. Daftar Transaksi}

G. Kesimpulan dan Saran

1. Kesimpulan

Berdasarkan penelitian yang dilakukan mengenai Aplikasi Web Distro Pak Eko Dengan Codeigniter maka dapat disimpulkan bahwa sistem dapat memudahkan customer dalam dapat memperoleh informasi secara jelas mengenai kaos distro yang tersedia, distro kaos distro online juga dapat mempromosikan menjual produknya secara lebih luas.

\section{Saran}

Dari semua hasil yang telah dicapai saat ini masih ada beberapa kekurangan, untuk itu penulis menyarankan yang mungkin dapat dipertimbangkan dikemudian hari untuk menambahkan lebih banyak lagi fitur dan semakin mempercantik tampilan agar lebih menarik.

\section{G. Daftar Pustaka}

Alexander, S. (2013). Web Programming Power Pack. Yogyakarta: MediaKom.

Andriansyah, D. (2016). Sistem Informasi Pendaftaran Event Dengan PHP Untuk Panduan Skripsi. Cirebon: Cv.Alva Solution.

Anhar, S. (2010). Panduan Menguasai PHP dan Mysql Secara Otodidak. Jakarta: MediaKita. 
Antika, Elly., Widiastuti, Ika., 2014, Pengembangan E-Commerce dan Strategi Promosi Online Batik Tulis Sumbersari untuk Memperluas Jaringan Pemasaran Melalui Internet, Konferensi Nasional Sistem dan Informatika (KNS\&I) 2014, ISSN: 1979-9845, STMIK STIKOM Bali, 7-8 November 2014, hal 278-283.

Bernadi, J., 2013, Aplikasi Sistem Informasi Penjualan Berbasis Web Pada Distro Velg YQ, ComTech, 4(2), hal 731-741.

Buana, I Komang Setia. 2014. Jago Pemrograman PHP Untuk Pemula dan Orang Awam. Jakarta Timur: Dunia Komputer.

Edy Winarno ST, M. A. (2013). Buku Sakti Pemrograman PHP. Jakarta: PT Elex Media Komputindo.

Fatmawati. (2016). Perancangan Sistem Pemesanan Catering Berbasis Web Pada Rumah Makan Tosuka Tangerang. Jurnal Teknik Komputer UBSI.

Joseph, Schumuller. 2011. Sams Teach. Yourself UML in 24 Hours. USA (United States of America): Publication Service, Inc.

Julisar., Miranda, Eka., 2013, Pemakaian ECommerce Untuk Usaha Kecil dan Menengah Guna Meningkatkan Daya Saing, ComTech, Vol. 4 No. 2, Desember 2013, hal 638-645.

Ragil, Wukil. (2010). Pedoman Sosialisai Prosedur Operasi Standar. Mitra Wacana Media. Jakarta

Sandi, Mulyana. 2014. Bikin Website Dengan Aplikasi-aplikasi Gratis Cepat, Mudah \& Murah. Yogyakarta: MediaKom.

Turban, E., King, D., Lang, J., 2010, Introduction to Electronic Commerce, Third Edition, Prentice-Hall, Inc.

V.P, S. d. (2016). Pemograman Web Dengan menggunakan PHP dan Framework Codeigniter . Yogyakarta: Deepublish.

Williams, L. 2006. Testing Overview Ana Black-Box Testing Techniques. Retrived from http://agile.csc.ncsu.edu/SEMaterials/ BlackBox.pdf

Xiaohui, Guo., Rong, Gao., JianYu, Wei., Chongning, Huo., 2014, Key Technology of Distributed E-Commerce System Architecture, TELKOMNIKA Indonesian Journal of Electrical Engineering, Vol.12, No.5, May 2014, DOI: http://dx.doi.org/10.11591/telkomnika.v1 $2 i 5.4346$, ISSN: $2302-4046$, hal $3987-$ 3993. 